\title{
Mitigasi Penyebaran Covid-19 Melalui Pemetaan Kepadatan Pemukiman, Mobilitas Penduduk dan Lingkungan Kelurahan Kadia Kota Kendari
}

\author{
Weka Widayati ${ }^{1}$, Sawaludin ${ }^{1}$, Anita Indriasary ${ }^{1}$, Weko Indira Romanti Aulia ${ }^{2}$, Saban Rahim ${ }^{1}$ \\ ${ }^{1}$ Jurusan Geografi, Fakultas Ilmu dan Teknologi Kebumian, Universitas Halu Oleo \\ ${ }^{2}$ Jurusan Teknik Arsitektur, Fakultas Teknik, Universitas Halu Oleo \\ e-mail : weka_widayati@yahoo.com, sawaludin_spimsc@uho.ac.id, \\ anitayulardhi@gmail.com, weko.indira@gmail.com, sabanrahim27@,gmail.com
}

\begin{abstract}
Abstrak: Isu pandemi Covid-19 menjadi perhatian dunia dan sampai saat ini belum diprediksi kapan akan berakhir. Penyebaran Covid-19 merubah pola interaksi dalam kurun waktu yang cepat dan drastis karena adanya pemberlakukan pembatasan pergerakan dan kegiatan manusia. Kota Kendari termasuk daerah yang terdampak penyebaran Covid-19 dan salah satu kelurahan yang terdampak dengan status zona merah adalah kelurahan Kadia. Dalam mengantisipasi penyebaran Covid-19 di kelurahan Kadia, perlu dilakukan mitigasi melalui pemetaan kepadatan pemukiman, mobilitas penduduk dan lingkungan. Tujuan kegiatan ini adalah melakukan mitigasi penyebaran Covid-19 melalui pemetaan kepadatan pemukiman, mobilitas penduduk dan lingkungan kelurahan Kadia. Metode yang digunakan dalam penelitian ini adalah survey dan overlay peta. Hasil penelitian menunjukan kepadatan pemukiman di kelurahan Kadia pada tingkat yang tinggi (25-34) pada RW 002, RW 007 dan RW 008. Kepadatan penduduk di kelurahan Kadia yang tinggi pada (62-92) pada RW 001 RT 002, RW 002, RW 007 RT 001 dan 003, RW 008 RT 003, dan RW 009 RT 003 . Tingkat mobilitas penduduk di kelurahan Kadia yang tinggi (90-174) pada RW 002 RT 002, RW 003 RT 001 dan 002, RW 004 RT 001, 002 dan 003, RW 005 RT 001, RW 006 RT 001, dan RW 007. Secara spasial kondisi lingkungan kelurahan Kadia didominasi oleh lahan terbangun dengan jumlah penduduk sebanyak 7775 jiwa. Berdasarkan hasil pemetaan kepadatan pemukiman, kepadatan penduduk, mobilitas penduduk dan lingkungan maka mitigasi tingkat potensial penyebaran Covid-19 di kelurahan Kadia difokuskan pada titik potensial yang tinggi (RW 002) dan titik potensial yang sedang (RW 007). Beberapa langkah mitgasi penyebaran Covid-19 yang dilakukan adalah memasang poster mitigasi penerapan protokol kesehatan dengan memakai masker, selalu mencuci tangan dengan sabun dan menjaga jarak.
\end{abstract}

Kata kunci : Mitigasi, Pandemi Covid-19, Pemetaan, Kelurahan Kadia

\begin{abstract}
The issue of the Covid-19 pandemic has become a worldwide concern and until now it has not been predicted when it will end. The spread of Covid-19 changed the pattern of interaction in a fast and drastic period due to the imposition of restrictions on human movement and activities. Kendari City is one of the areas affected by the spread of Covid-19 and one of the ward affected by the red zone status is Kadia Ward. In anticipating the spread of Covid-19 in the Kadia sub-district, it is necessary to carry out mitigation through mapping the density of settlements, population mobility, and the environment. The purpose of this activity is to mitigate the spread of Covid-19 through mapping the density of settlements, population mobility, and the Kadia urban village environment. The method used in this research is survey and map overlay. The results showed that the density of settlements in the Kadia village was at a high level (25-34) in RW 002, RW 007, and RW 008. The population density in the Kadia ward was high at (62-92) in RW 001, RT 002, RW 002, RW. 007 RT 001 and 003, RW 008 RT 003, and RW 009 RT 003. The level of population mobility in Kadia kelurahan is high (90-174) in RW 002 RT 002, RW 003 RT 001 and 002, RW 004 RT 001, 002 and 003, RW 005, RT 001, RW 006, RT 001, and RW 007. Spatially, the environmental condition of the Kadia ward is dominated by built-up land with a population of 7775 people. Based on the results of mapping settlement density, population density, population mobility, and the environment, mitigation of the potential level of Covid-19 spread in the Kadia ward is focused on high potential points (RW 002) and medium potential points (RW 007). Some of the steps to mitigate the spread of Covid-19 were putting up a mitigation poster for the implementation of the health protocol by wearing a mask, always washing hands with soap, and keeping a distance.
\end{abstract}

Keywords : Mitigation, Covid-19 Pandemic, Mapping, Kelurahan Kadia

Oktober--- 126 
| Vol.5 | No.2| 2021

\section{PENDAHULUAN}

Pandemi Covid-19 yang saat ini masih terus menjadi ancaman dan menganggu aktivitas masyarakat dan memunculkan banyak spekulasi yang tidak dapat dihindari. Sehingga meniscayakan Pemerintah, Kementerian, Lembaga, dan Institusi Pendidikan serta masyarakat untuk menahan dan mencegah pandemi covid-19 ini menjadi lebih massif dan berimplikasi luas. Promosi kesehatan, informasi publik terus digalakkan terhadap berbagai sektor terutama sektor perdagangan dan jasa sebagai pilar perekonomian di perkotaan. Satu tahun terakhir ini masyarakat di resahkan dengan pandemic Covid-19 yang membahayakan kesehatan masyarakat dan dapat menyebabkan kematian dan sudah memakan banyak korban, dengan berbagai macam peraturan baru yang dikeluarkan oleh pemerintah demi keamanan rakyat khususnya Indonesia. Adapun aturan dari pemerintah yang harus dilakukan adalah PSBB, Social Distancing, dan aturan lainnya. Penerapan PSBB dilakukan bagi kawasan yang sudah berzona merah (Engkus, E., 2020, Engkus, E., 2020, Kresna, A., \& Ahyar, J. 2020). Dalam upaya melawan pandemi Coronavirus Disease 2019 (COVID-19), ada beberapa jurus dasar yang disarankan Organisasi Kesehatan Dunia (WHO), diantaranya: tetap berdiam diri di rumah (karantina mandiri), rutin mencuci tangan, dan penjarakan fisik atau physical distancing. Pedoman ini menjadi mantra di seluruh dunia untuk mencegah penyebaran COVID-19 (Nugroho, 2020; Nurhalimah, N. 2020, Purbawati, C., Hidayah, L. N., 2020, Yanti, B., Wahyudi, E., 2020, Yunus, N. R., \& Rezki, A. 2020).

Permasalahan penyebaran Covid-19 masih terus menjadi perhatian pemerintah baik pemerintah pusat maupun pemerintah daerah. Beberapa hal yang perlu diperhatikan dalam menekan tingkat kenaikan angka yang positif covid-19, perlu dilakukan langkah-langkah preventif atau mitigasi penyebaran dengan pendekatan bimbingan pemetaan tingkat kepadatan pemukiman dan mobilitas penduduk di suatu wilayah. Kelurahan Kadia yang pernah masuk dalam kategori zona merah peresebaran Cocid-19 menjadi perhatian untuk dilakukan langkah-langkah mitigasi.

Pengembangan kecamatan Kadia berdasarkan rencana detail tata ruang diklasifikasikan dalam PPK CDB Teluk Kendari Kadia-Mandonga sebagai pusat pelayanan kota dengan fungsi pelayanan pemerintah kota serta perdagangan dan jasa. Kondisi eksisting di kelurahan Kadia terdapat aktifitas permukiman serta perdagangan dan jasa. Potensi unggulan kelurahan Kadia adalah sebagai pusat kegiatan masyarakat dan kegiatan perdagangan dan jasa. Semua kegiatan yang terdapat di kelurahan Kadia berkembang sejalan dengan perkembangan jumlah penduduk wilayah yang mempengaruhi kondisi lingkungan dan aktivitas penduduk. Kondisi demikian juga akan berimplikasi pada hubungannya dengan adanya pandemic coronavirus disease atau pandemic Covid-19. Dengan adanya pandemi Covid-19 diharapkan masyarakat tetap mematuhi protocol kesehatan pada aktivitas-aktivitas pemukiman maupun pada kegiatan perdagangan dan jasa. Sebagai kawasan yang padat pemukiman dan mobilitas penduduk yang tinggi, kelurahan Kadia rentan dengan aktivitas kerumunan masyarakat di lokasi-lokasi perdagangan maupun di lokasi pemukiman penduduk.

Tujuan studi ini adalah melakukan mitigasi penyebaran Covid-19 melalui pemetaan kepadatan pemukiman, mobilitas penduduk dan lingkungan kelurahan Kadia. Hasil kajian berupa informasi-informasi terkait penerapan protocol kesehatan yang dapat diterapkan pada titik lokasi potensial memiliki penyebaran Covid-19 yang tinggi.

\section{METODE PENELITIAN}

Lokasi penelitian ini di Kelurahan Kadia Kecamatan Kadia, Kota Kendari, Provinsi Sulawesi Tenggara. Letak geografis kelurahan Kadia yaitu $3^{\circ} 58^{\prime} 30^{\prime \prime}$ - $3{ }^{\circ} 59^{\prime} 0^{\prime \prime}$ S dan 122 $22^{\prime} 30^{\prime \prime} \quad$ - 12230'30" BT. Kelurahan Kadia yang meliputi 9 RW dan 
| Vol.5 | No.2| 2021

28 RT. Berikut lokasi kajian disajikan pada gambar 1 dibawah ini.

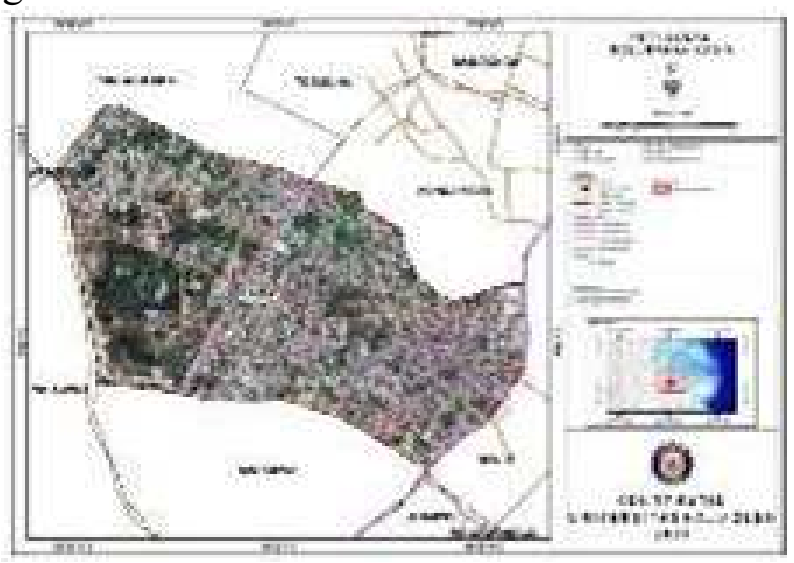

Gambar 1. Peta Lokasi Kajian Kelurahan Kadia

Dalam melakukan penelitian dibutuhkan alat yang digunakan untuk melakukan penelitian tersebut. Alat penelitian tersebut terbagi menjadi dua golongan yaitu perangkat keras dan perangkat lunak. Daftar dari masing-masing perangkat yaitu: Perangkat Keras (Laptop, GPS Handheld, Kamera) dan Perangkat Lunak (ArcGIS 10.3, Microsoft Office 2010). Sedangkan bahan yang digunakan untuk tercapainya proses penelitian yaitu: Citra Resolusi Tinggi, Batas Administrasi kelurahahn Kadia dan Data Lapangan (Ground Check) yang diperoleh saat survey lapangan.

Jenis data yang digunakan dalam penelitian ini adalah data primer dan data sekunder. Data primer merupakan data yang diperoleh langsung dari lapangan atau melalui observasi. Sedangkan data sekunder merupakan $d$ ata pendukung yang diperoleh melalui studi pustaka maupun dari instansiinstansi terkait dengan penelitian antara lain, Badan Pusat Statistik, Dinas Pekerjaan Umum dan Penataan Ruang, Kantor Kelurahan dan Kantor Kecamatan.

Metode penelitian yang digunakan adalah metode deskriptif kuantitatif dengan pendekatan analisis spasial dengan bantuan alat analisis GIS (Geography Information System). Analisis spasial dilakukan dengan cara overlay atau menumpangtindihkan parameter-parameter yang dikaji. Datadata yang digunakan dalam penelitian ini diperoleh dengan survei primer dan survei sekunder. Teknik analisis overlay adalah suatu sistem informasi dalam bentuk grafis yang dibentuk dari penggabungan berbagai peta individu (memiliki informasi/database yang spesifik). Data awal yang diperlukan terdiri dari peta-peta tematik yaitu peta administrasi dan peta penggunaan lahan eksisting. Sebagai hasil akhir dari overlay peta dilakukan penentuan titik mitigasi potensial penyebaran Covid-19 di Kelurahan Kadia.

\section{HASIL DAN PEMBAHASAN}

Berdasarkan survey lapangan terhadap obyek pengamatan maka dalam kajian ini menghasilkan peta penggunaan lahan, peta persil bangunan, peta kepadatan pemukiman, peta kepadatan penduduk, peta mobilitas penduduk, peta profil lingkungan dan peta mitigasi titik potensial penyebaran Covid-19 di kelurahan kadia Kota Kendari.

Hasil hasil digitasi citra terbaru tahun 2020, penggunaan lahan di Kelurahan Kadia terdapat 6 (enam) jenis penggunaan lahan terdiri dari lahan terbangun (144,53 ha), lahan terbuka $(5,15 \mathrm{ha})$, perkebunan $0,84 \mathrm{ha})$, rawa $(0,72$ ha), semak belukar $(1,15$ ha $)$ dan vegetasi (67,23 ha).

Tabel 1. Penggunaan Lahan Kelurahan Kadia tahun 2020

\begin{tabular}{llc}
\hline No & Pengunaan Lahan & Luas (Ha) \\
\hline 1 & Lahan Terbangun & 144,53 \\
\hline 2 & Lahan Terbuka & 5,15 \\
\hline 3 & Perkebunan & 0,84 \\
\hline 4 & Rawa & 0,72 \\
\hline 5 & Semak Belukar & 1,15 \\
\hline 6 & Vegetasi & 67,23 \\
\hline & Jumlah & $\mathbf{2 1 9 , 6 2}$ \\
\hline
\end{tabular}

Sumber : Hasil Analisis Pengolahan Data Tahun 2021

Secara spasial penggunaan lahan di Kelurahan Kadia Kota Kendari dapat dlihat pada gambar 2 berikut. 
| Vol.5 | No.2| 2021

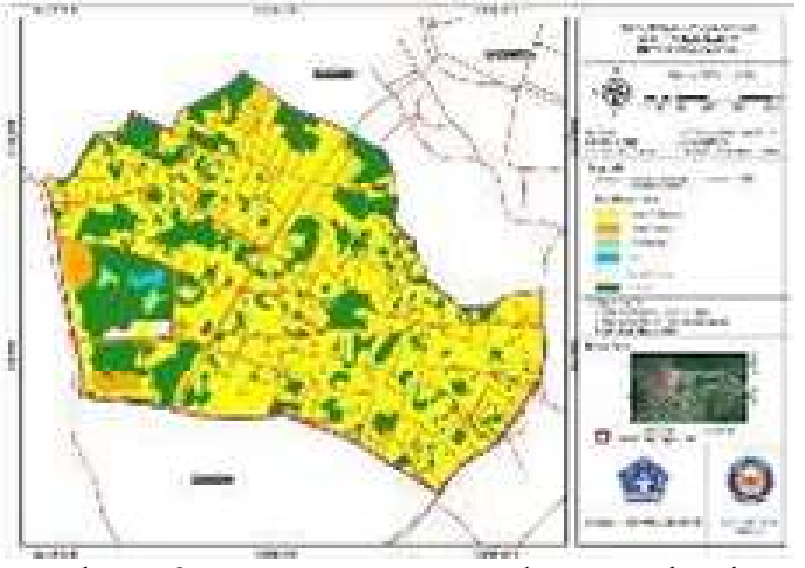

Gambar 2. Penggunaan Lahan Kelurahan Kadia

Berdasarkan hasil analisis pemetaan penggunaan lahan menunjukan bahwa lahan terbangun dominan di Kelurahan Kadia, selanjutnya vegetasi dan lahan terbuka. Penggunaan lahan di Kelurahan Kadia saat ini terjadi perubahan dari lahan terbuka dan vegetasi cenderung menjadi lahan terbangun. Penggunaan lahan di kawasan perkotaan cenderung mengalami perubahan fungsi kawasan menjadi kawasan terbangun (Misa, 2018). Rencana penggunaan lahan mendorong peningkatan dan pelestarian kota saat ini dan ke depan, dan mengupayakan perluasan perkembangan kota yang teratur, efisien dan rasional di kawasan yang belum berkembang (Makarau, 2011). Kenyataan pada umumya di kota-kota selalu mengalami aglomerasi penduduk dan berbagai kegiatan ekonomi, politik maupun kebudayaan yang cukup pesat. Bahkan terjadi pengelompokan kegiatan di suatu lokasi tertentu, sehingga di kota akan dijumpai berbagai pusat kegiatan, seperti perkantoran, perdagangan, kampus, industri dan sebagainya. Kelurahan Kadia menunjukan eksistensinya sebagai bagian dari pengembangan kecamatan Kadia berdasarkan rencana detail tata ruang diklasifikasikan dalam PPK CDB Teluk Kendari Kadia-Mandonga menjadi pusat pelayanan kota dengan fungsi pelayanan pemerintah kota serta perdagangan dan jasa.

Pemetaan terhadap kepadatan pemukiman dilakukan terlebih dahulu digitasi persil bangunan. untuk menentukan kepadatan pemukiman dengan membandingkan antara jumlah bangunan dengan luasan wilayah per $\mathrm{RW} / \mathrm{RT}$. Secara spasial peta persil bangunan dan kepadatan pemukiman dapat dilihat pada gambar 3 dan 4 dibawah ini.

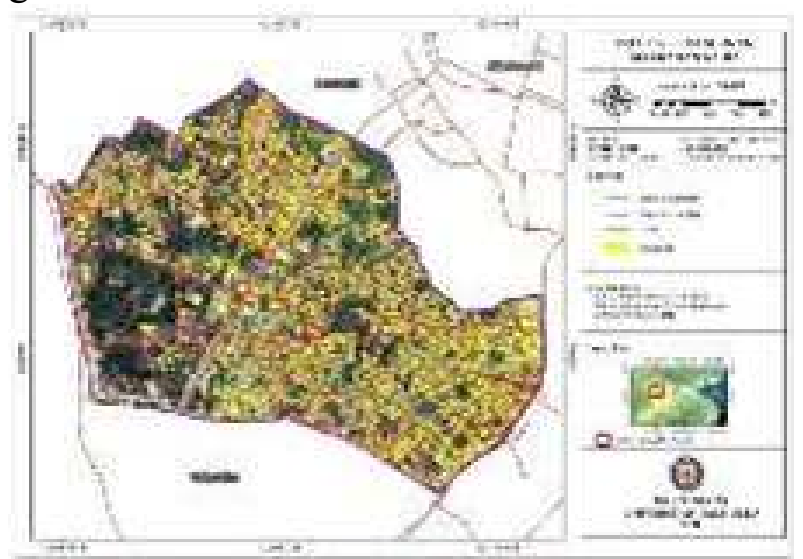

Gambar 3. Peta Persil Bangunan Kelurahan Kadia

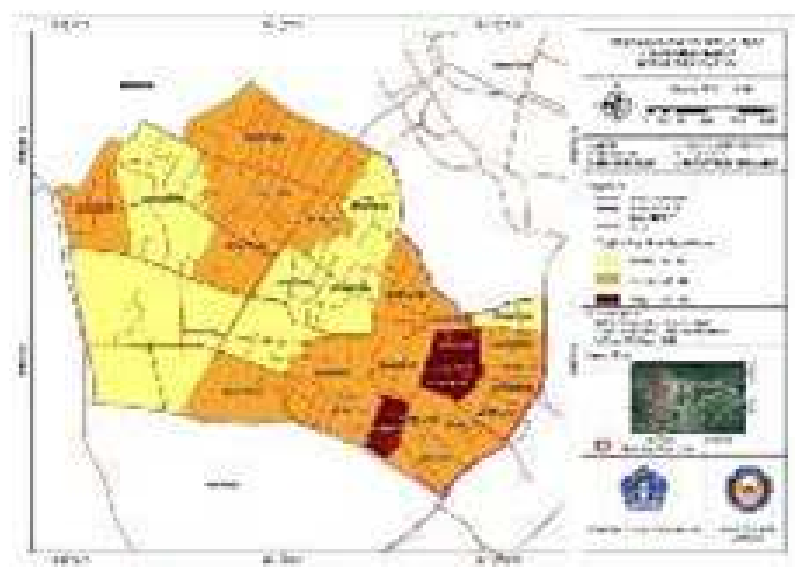

Gambar 4. Peta Kepadatan Pemukiman Kelurahan Kadia

Berdasarkan hasil pemetaan persil bangunan dan kepadatan pemukiman menunjukan bahwa tingkat kepadatan pemukiman di kelurahan Kadia pada tingak rendah (6-14) pada RW 001 RT 001, RW 003 RT 002 dan RT 003, RW 004 RT 004, RW 005 RT 002, RW 006 RT 001. Tingkat kepadatan pemukiman sedang (1524) pada RW 001 RT 002 dan RT 003, RW 002 RT 001, RW 003 RT 001, RW 004 RT 001, RT 002 dan RT 003, RW 005 RT 001 dan RT 003, RW 006 RT 002, RW 007 RT 001, RT 002 dan RT 003, RW 008 RT RT 001 dan RT 002, RW 009 RT 001, RT 002, RT 003. Sementara itu tingkat kepadatan pemukiman tinggi (25-34) pada RW 002 RT 002 dan RT 003, RW 007 RT 004 dan RW 008 RT 003. Kepadatan pemukiman adalah perbandingan antara jumlah rumah tangga dengan luasannya di suatu wilayah pemukiman, dimana penduduknya mengelompok membentuk suatu pola tertentu yang sesuai dengan faktor-faktor yang 
| Vol.5 | No.2| 2021

mempengaruhi yaitu pertumbuhan penduduk, kondisi alam suatu wilavah, sosial ekonomi penduduk serta sarana dan prasarana yang tersedia.

Kepadatan permukiman relatif berbeda antara kawasan yang satu dengan kawasan yang lain dengan penggunaan ruangan relatif baik dan ada kawasan dengan penggunaan ruang relatif kurang baik ditandai dengan keteraturan permukiman, keamanan permukiman, rasa nyaman bertempat tinggal dan kelancaran aksesibilitas dan mobilitas dalam kawasan permukiman (Mustika, 2018).

Selanjutnya dilakukan pemetaan mobilitas penduduk di Kelurahan Kadia dengan terlebih dahulu melakukan pemetaan kepadatan penduduk dan mengidentifikasi pekerjaan penduduk untuk menentukan mobilitasnya. Secara spasial peta kepadatan penduduk dan mobilitas penduduk di Kelurahan Kadia dapat dilihat pada gambar 5 dan gambar 6 dibawah ini.

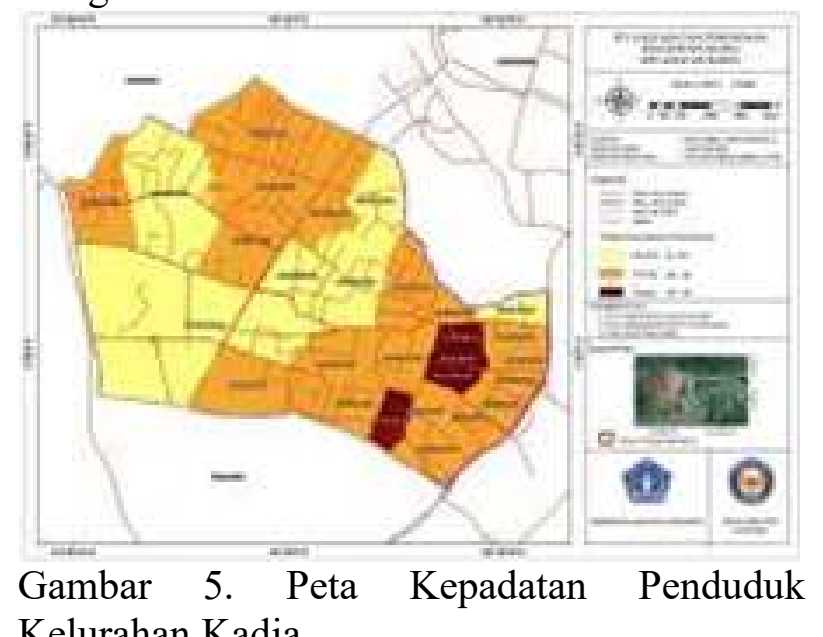

Kelurahan Kadia

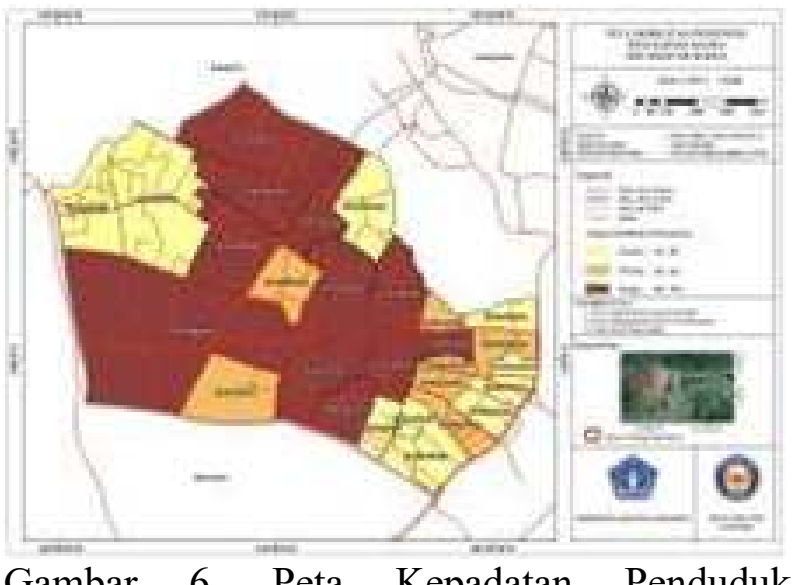

Gambar 6. Peta Kepadatan Penduduk Kelurahan Kadia
Berdasarkan hasil pemetaan kepadatan penduduk dan mobilitas penduduk menunjukan bahwa tingkat kepadatan penduduk di Kelurahan Kadia berkisar 6-34 jiwa per RW RT. Kepadatan penduduk rendah (6-14 jiwa) pada RW 001 RT 001, RW 003 RT 002 dan RT 003, RW 004 RT 004, RW 005 RT 002, dan RW 006 RT 001. Kepadatan penduduk sedang (15-24 jiwa) pada RW 001 RT 002 dan RT 003, RW 002 RT 001, RW 003 RT 001, RW 004 RT 001, RT 002 dan RT 003, RW 005 RT 001 dan RT 003, RW 006 RT 002, RW 007 RT 001, RT 002 dan RT 003, RW 008 RT 001 dan RT 002, dan RW 009 RT 001, RT 002 dan RT 003. Kepadatan penduduk tinggi (25-34 jiwa) pada RW 002 RT 002 dan RT 003, RW 007 RT 004, dan RW 008 RT 003.

Sementara itu tingkat mobilitas penduduk berkisar 10-174 penduduk per RW dengan tingkat mobilitas penduduk rendah (10-50) di kelurahahn Kadia terdapat pada RW 001 RT 001 dan RT 003, RW 004 RT 004, RW 005 RT 002 dan RT 003, RW 007 RT 004, RW 008 RT 001 dan RT 002, dan RW 009 RT 002 dan RT 003. Tingkat mobilitas penduduk sedang (50-90) di kelurahan Kadia terdapat pada RW 001 RT 002, RW 002 RT 001 dan RT 003, RW 003 RT 003, RW 006 RT 002, RW 008 RT 003, dan RW 009 RT 001. Tingkat mobilitas penduduk tinggi (90174) di kelurahan Kadia terdapat pada RW 002 RT 002, RW 003 RT 001 dan RT 002, RW 004 RT 001, RT 002 dan RT 003, RW 005 RT 001, serta RW 007 RT 001, RT 002 dan RT 003. Tingkat mobilitas penduduk di pengaruhi oleh jenis pekerjaan tiap penduduk yang bekerja di luar wilayah kelurahan Kadia. Kecenderungan mobilitas pergerakan penduduk di Kelurahan Kadia yang paling besar adalah penduduk yang berprofesi kerja sebagai pegawai negeri sipil (PNS) lingkup pemerintah dan pedagang yang beraktivitas di luar wilayah kelurahan Kadia. Todaro (1996) menyatakan pendapatnya bahwa perpindahan penduduk merupakan suatu proses yang sangat selektif, yang mempengaruhi setiap individu dengan ciri-ciri ekonomi, sosial, pendidikan dan demografi tertentu untuk melakukan perpindahan. Bentuk mobilitas yang terjadi pada sebagian besar penduduk di kelurahan 
Kadia adalah mobilitas non permanen berupa mobilitas ulang-alik.

Salah satu aspek yang sangat penting dalam mitigasi penyebaran Covid-19 di kelurahan Kadia adalah memetakan lingkungan kelurahan. Hasil pemetaan berupa overlay kondisi penggunaan lahan, jumlah penduduk dan fasilitas-fasilitas umum yang ada untuk menggambarkan profil lingkungan kelurahan Kadia. Secara spasial peta profil lingkungan kelurahan Kadia pada gambar 7 berikut.

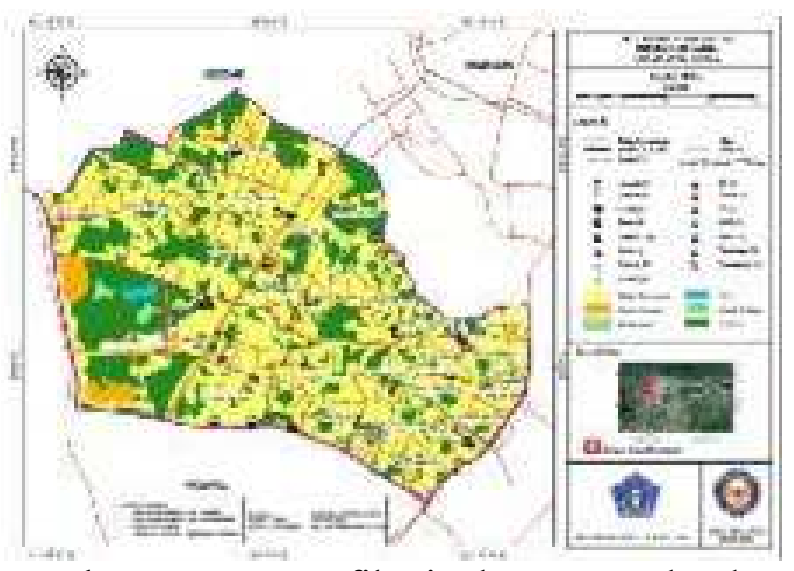

Gambar 7. Peta Profil Lingkungan Kelurahan Kadia

Berdasarkan hasil analisis overlay penggunaan lahan dan fasilitas umum maka secara keselurahan lingkungan kelurahan Kadia secara rinci menunjukan fasilitasfasiltas umum terdapat kantor sebanyak 8 , sekolah sebanyak 6 yang terdiri dari TK (1), PAUD (1), SD, SMP (2), SMK (1), puskesmas sebanyak 1, Apotek sebanyak 5, klinik sebanyak 1, masjid sebanyak 14 , gereja sebanyak 3, pura sebanyak 1, pesantren sebanyak 1, pasar 1 lokasi, Gym 1 dengan jumlah penduduk sebanyak 7775 jiwa dengan luas sebesar 2,19 $\mathrm{km}^{2}$.

Hasil pemetaan kepadatan pemukiman, mobilitas penduduk dan lingkungan kelurahan Kadia maka dirumuskan rencana mitigasi pada lokasi yang potensial penyebaran Covid-19. Mitigasi penyebaran Covid-19 melalui pemetaan pada titik potensial dapat dilihat pada gambar 8 berikut.
| Vol.5 | No.2| 2021

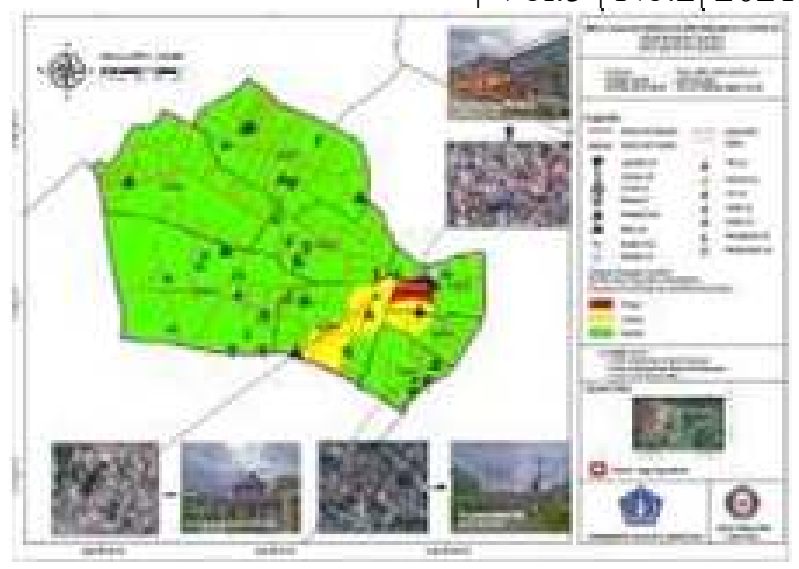

Gambar 8. Peta Mitigasi Penyebaran Potensial Covid-19 Kelurahan Kadia

Berdasarkan hasil pemetaan kepadatan pemukiman, kepadatan penduduk, mobilitas penduduk dan lingkungan maka mitigasi tingkat potensial penyebaran Covid-19 di kelurahan Kadia difokuskan pada titik potensial yang tinggi (RW 002) dan titik potensial yang sedang (RW 007). Pada RW 002 dan RW 007 memiliki kepadatan pemukiman dan mobilitas penduduk yang tinggi.

\section{KESIMPULAN}

Mitigasi penyebaran Covid-19 di Kelurahan Kadia sangat penting untuk dilaksanakan mengingat kelurahan Kadia merupakan salah satu wilayah yang termasuk dalam zona merah dan memiliki kepadatan pemukiman tinggi, mobilitas penduduk yang tinggi dan banyak aktivitas perdagangan dan jasa. Hasil pemetaan kepadatan pemukiman, kepadatan penduduk, mobilitas penduduk dan lingkungan, titik mitigasi tingkat potensial penyebaran Covid-19 di kelurahan Kadia difokuskan pada titik potensial yang tinggi (RW 002) dan titik potensial yang sedang (RW 007). Beberapa langkah mitgasi penyebaran Covid-19 yang dilakukan adalah memasang poster mitigasi penerapan protokol kesehatan dengan memakai masker, selalu mencuci tangan dengan sabun dan menjaga jarak.

\section{Ucapan Terimakasih}

Ucapan terima kasih kami sampaikan kepada Universitas Halu Oleo yang telah memberikan dan memfasilitasi untuk hibah internal tahun 2021 sehingga bisa dimanfaatkan dalam kajian mitigasi 
| Vol.5 | No.2| 2021

penyebaran Covid-19 melalui pemetaan kepadatan pemukiman, mobilitas penduduk dan lingkungan kelurahan Kadia Kota Kendari.

\section{DAFTAR PUSTAKA}

Engkus, E., Suparman, N., Tri Sakti, F., \& Saeful Anwar, H. (2020). Covid-19: Kebijakan mitigasi penyebaran dan dampak sosial ekonomi di Indonesia. $L P 2 M$.

Herlan, H., Efriani, E., Sikwan, A., Hasanah, H., Bayuardi, G., Listiani, E. I., \& Yulianti, Y. (2020). Keterlibatan Akademisi Dalam Menanggulangi Dampak Covid-19 Terhadap Masyarakat Melalui Aksi Berbagi Sembako. JCES (Journal of Character Education Society), 3(2), 266-276.

Kresna, A., \& Ahyar, J. (2020). Pengaruh Physical Distancing Dan Social Distancing Terhadap Kesehatan Dalam Pendekatan Linguistik. Jurnal Syntax Transformation, 1(4), 14-19.

Makarau, V.H., 2011. Penduduk, Perumahan Permukiman Perkotaan, dan Pendekatan Kebijakan Suatu Tinjauan. Jurnal Sabua. Vol. 3 No. 1 : 53-37

Misa, D.P.P., Moniaga, I.L., Lahamendu, V., 2018. Penggunaan Lahan Kawasan Perkotaan Berdasarkan Fungsi Kawasan, Studi Kasus : Kawasan Perkotaan Kecamatan Air Madidi. Jurnal Spasial. Vol. 5, No. 2. pp. 171178.

Mustika, F., Isya, M., Achmad, A., 2018. Analisis Pengaruh Kepadatan Permukiman terhadap Pelayanan Infrastruktur Di Kota Banda Aceh. Jurnal Arsip Rekayasa Sipil dan Perencanaa 1(4):138-147.

Nugroho, A., Fian A., Fahmi, M., Wardoto, Y., 2020. Rentan dan Terapapar Bahaya : Krisis Hunian Layak di Tengah Pandemi. Lokataru Foundation. Jakarta.

Nurhalimah, N. (2020). Upaya Bela Negara Melalui Sosial Distancing Dan Lockdown Untuk Mengatasi Wabah Covid-19 (Efforts to Defend the
Country Through Social Distancing and Lockdown to Overcome the COVID-19 Plague). Available at SSRN 3576405.

Purbawati, C., Hidayah, L. N., \& Markhamah, M. (2020). Dampak Social Distancing Terhadap Kesejahteraan Pedagang Di Pasar Tradisional Kartasura Pada Era Pandemi Korona. Jurnal Ilmiah Muqoddimah: Jurnal Ilmu Sosial, Politik dan Hummanioramaniora, 4(2), 156-164.

Todaro, M.P., 1996. Kajian Ekonomi Migrasi Internal di Negara Berkembang, (Seri Terjemahan no. 25). Yogyakarta: Pusat Penelitian Kependudukan-Universitas Gadjah Mada.

Yanti, B., Wahyudi, E., Wahiduddin, W., Novika, R. G. H., Arina, Y. M. D. A., Martani, N. S., \& Nawan, N. (2020). Community Knowledge, Attitudes, and Behavior Towards Social Distancing Policy As Prevention Transmission of Covid-19 in Indonesia. Jurnal Administrasi Kesehatan Indonesia, 8(2), 4-14. 